Universidade Tecnológica Federal do Paraná - UTFPR

Campus Ponta Grossa - Paraná - Brasil

ISSN: 1981-3686/ v. 9, n. 1: p. 1647-1659, 2015

D.o.I.http://dx.doi.org/10.3895/rbta.v9n1.1699
Revista Brasileira de Tecnologia

Agroindustrial

\title{
CARACTERIZAÇÃO FÍSICO-QUÍMICA DE FRUTOS DOS GENÓTIPOS DE UMBU-CAJAZEIRAS ORIUNDOS DA MICRORREGIÃO DE IGUATU, CE
}

\section{UMBU-CAJAZEIRAS PHYSICAL-CHEMISTRY IN THE SOUTHERN REGION OF IGUATU, CE}

Leirson Rodrigues da Silva ${ }^{1}$, Ricardo Elesbão Alves ${ }^{2}$, Silvanda de Melo Silva ${ }^{3}$ e Dijauma Honório Nogueira ${ }^{4}$

${ }^{1}$ Universidade Federal Rural do Semiárido, Mossoró-RN, rodriguesleirson@ yahoo.com.br; ${ }^{2}$ Embrapa Agroindústria de Alimentos (CNPAT), Fortaleza-CE; ${ }^{3}$ Universidade Federal da Paraíba, Areia-PB; ${ }^{4}$ Instituto Federal de Educação do Ceará, Iguatu-CE.

\section{Resumo}

A umbu-cajazeira é uma árvore frutífera de ocorrência espontânea no semiárido nordestino e seus frutos são explorados apenas de forma extrativista. Este trabalho teve como objetivo avaliar a qualidade de frutos de umbu-cajazeiras (Spondias sp.), oriundos dos diferentes genótipos, por meio de caracterização físico-química. A colheita foi realizada para todos os genótipos no mesmo dia, no mês de março de 2007, sendo os frutos retirados no estádio de maturação comercial com auxílio de um gancho, onde o indicativo de maturidade era a cor amarelo-alaranjada da casca. Foram colhidos vinte frutos dos vinte genótipos de umbu-cajazeiras provenientes do Município de Iguatu, $C E$ e avaliados quanto: açúcares redutores, $\mathrm{pH}$, amido, pectina total, carotenoides totais, flavonoides amarelos e polifenóis extraíveis totais. De uma maneira, houve uma variação entre os genótipos, para todas as características físico-químicas avaliadas. Com relação aos atributos físico-químicos avaliados, os frutos em geral apresentaram pH médio de 2,77, alto teor de açúcares redutores (7,84\%), baixo para amido (0,17\%) e pectinas (0,37\%), A média geral de carotenoides

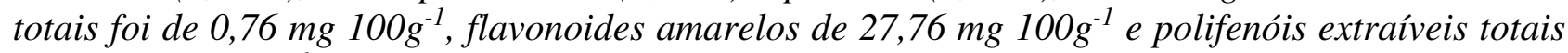
de 29,63 mg $100 \mathrm{~g}^{-1}$, fator este de grande importância para a indústria.

Palavras-chave: Spondias sp., atributos, qualidade; semiárido.

\section{Introdução}

A umbu-cajazeira (Spondias sp.), pertence à família Anacardiaceae e ao gênero Spondias, é considerada um híbrido natural entre o umbuzeiro e a cajazeira (GIACOMETTI, 1993) e tem origem desconhecida, apresentando características de planta xerófita encontrada em plantios desorganizados disseminados nos Estados do Nordeste.

O gênero Spondias possui 18 espécies distribuídas nos neotrópicos, Ásia e Oceania. No Nordeste brasileiro, destacam-se as espécies: Spondias mombin L. (cajazeira), Spondias purpurea L. (cirigueleira), Spondias cytherea Sonn. (cajaraneira), Spondias tuberosa Arr. Câm. (umbuzeiro), 
além das Spondias sp. (umbu-cajazeira e umbugueleira), que vem despertando interesse, especialmente para a agroindústria (MITCHEL e DALY, 1995).

O fruto da umbu-cajazeira é caracterizado como uma drupa arredondada, de cor amarela, casca fina e lisa, com endocarpo chamado "caroço", grande, branco, suberoso e enrugado, localizado na parte central do fruto, no interior do qual se encontram os lóculos, que podem ou não conter uma semente. A umbu-cajazeira apresenta cerca de $90 \%$ dos endocarpos desprovidos de sementes (SOUZA et al., 1997) o que torna inviável a sua propagação sexual, sendo tradicionalmente propagada pelo método vegetativo assexuado, por estacas de $35 \mathrm{~cm}$ de comprimento e 1,5 cm de diâmetro (LOPES, 1997).

Os frutos possuem excelente sabor, aroma e boa aparência, muito consumidos na forma "in natura", apresentando rendimento médio de 55 a $65 \%$ em polpa, com potencial para a sua utilização na forma processada como polpa congelada, sucos, néctares e sorvetes (LIMA et al., 1990).

A espécie umbu-cajazeira, também conhecida como cajarana ou cajarana do sertão, ainda não foi definida botanicamente. Pode ser encontrada nas diversas regiões em seu estado nativo, sem qualquer cuidado de cultivo. Raramente são verificados cultivos racionais, usando-se comumente como cercas vivas, para sombreamento ou quebra-ventos. A umbu-cajazeira apresenta porte elevado e copa aberta (NORONHA, 1997).

O consumo de frutas na alimentação humana tem deixado de ser somente um prazer para converte-se em uma necessidade, dadas às boas características que as mesmas têm para a saúde e bem-estar do homem. As frutas são fontes muito boas de energia, carboidratos, diversas vitaminas, minerais e produtos com propriedades bioativas, além do que proporcionam variedade e sabor a dieta, constituindo parte importante desta (ALVES et al., 2006).

De acordo com Baiardi et al. (2001) o conceito de qualidade está associado ao sistema de "Produção Integrada de Frutas" (PIF), que seria a produção de frutas de forma econômica e com máximo de respeito ao meio ambiente e à saúde do consumidor e produtor. Isso se daria por meio da minimização do uso de agroquímicos e mediante a integração de práticas de manejo de solo.

Ao se estudar a qualidade do umbu-cajá, várias são as características que podem ser avaliadas, tais como: $\mathrm{pH}$, açúcares redutores, amido, pectina total, carotenoides totais, flavonoides amarelos e polifenóis extraíveis totais. Cada uma das características é avaliada de maneira diferente, servindo para indicar a época de colheita, o estádio de maturação mais adequado para a colheita do fruto e, principalmente, o atributo de sua qualidade (LIMA et al., 2002).

Mediante ao exposto, o presente trabalho teve como objetivo avaliar a qualidade de frutos de umbu-cajazeiras, oriundos dos diferentes genótipos, pela caracterização físico-química. 


\section{Materiais e Métodos}

O trabalho foi realizado com vinte frutos de vinte genótipos de umbu-cajazeira previamente identificados localizadas nas comunidades de Cruiri (P1, P2, P3, P4 e P5), Quixoá (P6, P7, P8, P9 e P10), Alencar (P11, P12, P13, P14 e P15) e Vila Cajazeiras (P16, P17, P18, P19 e P20), pertencentes à Microrregião de Iguatu, localizada na Mesorregião Centro Sul do estado do Ceará.

Os frutos foram colhidos nas primeiras horas do dia, utilizando-se de procedimento através de seleção visual, tomando-se como base o estádio onde às características sensoriais do fruto eram máximas ao consumidor. A colheita foi realizada para todos os genótipos no mesmo dia, no mês de março de 2007, sendo os frutos retirados com auxílio de um gancho, no estádio de maturação comercial, onde o indicativo de maturidade era a cor amarelo-alaranjada da casca.

Posteriormente, foram transportados para o Laboratório de Fisiologia e Tecnologia PósColheita da Embrapa Agroindústria Tropical, localizado em Fortaleza, CE e mantidos congelados em freezer doméstico a aproximadamente $-20{ }^{\circ} \mathrm{C}$ até o momento do despolpamento. Essa despolpa se realizou manualmente, que através do auxílio de faca foram retiradas as partes comestíveis (polpa + casca) do fruto, pesadas em balança semi-analítica (MARK 3100). As polpas obtidas foram acondicionadas em potes plásticos escuros e mantidas sob congelamento para posterior avaliação das características físico-químicas quanto a: açúcares redutores, pH, amido, pectina total, carotenoides totais, flavonoides amarelos e polifenóis extraíveis totais.

Para as avaliações físico-químicas, a determinação para açúcares redutores foi realizada segundo Miller (1959) utilizando o ácido 3-5 dinitrossalicílico (DNS). Pesou-se 2,5 g de polpa diluída em $50 \mathrm{~mL}$ de álcool etílico a $80 \%$. Repouso por 15 minutos e em seguida filtração em papel de filtro qualitativo. Tomou-se $0,2 \mathrm{~mL}$ para a quantificação. Os resultados expressos em \%. O pH foi medido diretamente na polpa, logo após o processamento, utilizando potenciômetro (Mettler, modelo DL 12), aferido com tampões de pH 4,0 e 7,0 conforme AOAC (1992).

Para o amido, a extração foi feita por hidrólise ácida, conforme método descrito pela (AOAC, 1992), com algumas adaptações. Utilizou-se amostra de 5,0 g de polpa diluída em $50 \mathrm{~mL}$ de água destilada. Esta foi centrifugada, durante $10 \mathrm{~min}$, por três vezes, a $15.000 \mathrm{rpm}$, com o descarte do sobrenadante. Ao resíduo, foram adicionados $150 \mathrm{~mL}$ de água destilada e $5 \mathrm{~mL}$ de ácido clorídrico P.A. O preparo foi deixado em fervura durante 2 h, sob refluxo. Em seguida, foi resfriado e neutralizado com solução de carbonato de sódio a $20 \%$. O volume foi completado para $50 \mathrm{~mL}$, com água destilada e filtrado. A partir do filtrado, transferiu-se alíquota de $1,5 \mathrm{~mL}$ do extrato para tubos de ensaio, adicionando-se, em cada, 1,0 mL de água destilada, 1,0 mL de solução de ácido dinitrosalicílico (DNS), seguido da homogeneização e colocado em banho-maria a $100{ }^{\circ} \mathrm{C}$ por cinco minutos e imediatamente colocados em banho de gelo. Em seguida, efetuou-se a leitura em 
espectrofotômetro (Spectronic Genesys 2) com comprimento de onda de $540 \mathrm{~nm}$. Os resultados obtidos foram multiplicados pelo fator 0,90 para a determinação do amido em percentagem.

Para a pectina total, a extração foi realizada pelo método do m-hidroxidifenil segundo procedimento descrito por Mccready e Mccomb (1952). Foram utilizados 2,5 g de polpa, adicionando $12,5 \mathrm{~mL}$ de etanol $95 \%$ e homogeneizado (Turrax), deixando em repouso por 30 minutos em geladeira e em seguida centrifugados. Em seguida, foram lavadas duas vezes o resíduo com $\pm 5 \mathrm{~mL}$ de etanol $75 \%$ cada vez. Transferiu-se o resíduo para um béquer com água (+/- 40 $\mathrm{mL}$ ), ajustando o pH para 11,50 com $\mathrm{NaOH}$ 1,0 $\mathrm{N}$ e logo após foram deixados em repouso em geladeira por 30 minutos, ajustando o $\mathrm{pH}$ para 5,0-5,5 com ácido acético glacial diluído (15 mL/50 $\mathrm{mL}$ ). Foram adicionados a amostra 0,1 g de pectinase, agitando-se em um agitador por uma hora. Filtrou-se a vácuo e diluiu-se o sobrenadante para $100 \mathrm{~mL}$ com água destilada em um balão volumétrico. Tomou-se uma alíquota do filtrado de $0,25 \mathrm{~mL}$ para reação com solução de ácido sulfúrico/tetraborato de sódio. Os tubos de ensaio contendo a amostra foram colocados em banho de gelo e após receberem o reativo, foram agitados e colocados em banho-maria a $100{ }^{\circ} \mathrm{C}$ por cinco minutos e imediatamente devolvidos ao banho de gelo. Em seguida, adicionou-se 0,06 mL de mhidroxidifenil para desenvolvimento de cor. Manteve-se em repouso por 10 minutos e após esse tempo realizou-se a leitura em espectrofotômetro (Spectronic Genesys 2) com comprimento de onda de $520 \mathrm{~nm}$ e o resultado expresso em $\%$.

Os carotenoides totais foram determinados pelo método de Higby (1962). Em recipiente de aço inox, foram colocados 2,0 de polpa, 6,0 mL de álcool isopropílico e 2,0 mL de hexano, seguido de agitação por dois minutos. O conteúdo foi transferido para funil de separação de $125 \mathrm{~mL}$ de cor âmbar, onde se completou o volume com água. Deixou-se em repouso por 30 minutos, seguindo-se a lavagem do material. Repetiu-se esta operação por mais duas vezes, Filtrou-se o conteúdo com algodão pulverizado com sulfato de sódio anidro para um balão volumétrico de $10 \mathrm{~mL}$ envolto com alumínio, onde foram adicionados $2,0 \mathrm{~mL}$ de acetona e completado o volume com hexano. As leituras foram feitas em espectrofotômetro a $450 \mathrm{~nm}$ e os resultados expressos em mg $100 \mathrm{~g}^{-1}$, calculados através da formula: (A x 100)/(250 x L x W), onde:

$\mathrm{A}=$ absorbância; $\mathrm{L}=$ comprimento de onda em $\mathrm{nm}$ e $\mathrm{W}=$ quantidade da amostra original no volume final da diluição.

As determinações para flavonoides amarelos seguiram a metodologia de Francis (1982). Tomou-se 1,0 g da polpa em recipiente de aço inox, adicionando-se aproximadamente $30 \mathrm{~mL}$ de solução extratora de etanol $95 \%$ mais $\mathrm{HCl}$ 1,5N na proporção de 85:15 (v/v) respectivamente. A amostra foi triturada em homogeneizador de tecidos tipo "Turrax" por dois minutos e transferida para o balão volumétrico (cor âmbar) de $50 \mathrm{~mL}$, sendo o volume completado com solução extratora. Deixou-se descansando por uma noite na geladeira sob ausência de luz. Em seguida filtrou-se para 
um Becker, envolto em papel alumínio. Imediatamente, procedeu-se a leitura no espectrofotômetro. Para os flavonoides amarelos realizou-se leitura a $374 \mathrm{~nm}$, calculado através da fórmula: fator de diluição x absorbância/76,6. Os resultados foram expressos em mg $100 \mathrm{~g}^{-1}$ de polpa.

A determinação de polifenóis extraíveis totais foi feita conforme descrito pelo método de Larrauri et al. (1997). Tomou-se em um becker $30 \mathrm{~g}$ da amostra, adicionando $40 \mathrm{~mL}$ de metanol 50 $\%$ e deixou-se extraindo por uma hora. Em seguida, foram centrifugados a $15.000 \mathrm{rpm}$ durante 15 minutos. O sobrenadante foi filtrado e transferido para um balão volumétrico de $100 \mathrm{~mL}$, o resíduo foi transferido para um Becker adicionando $40 \mathrm{~mL}$ de acetona $70 \%$, deixando-se extrair por uma hora. Em seguida foi repetida a centrifugação e o sobrenadante foi filtrado e adicionado juntamente ao balão volumétrico que já continha o sobrenadante da primeira extração, completando o volume com água destilada. Em tubos de ensaio colocou-se uma alíquota do extrato de 1,0 mL, mais 1,0 mL do reagente de Folin Ciocalteu, $2 \mathrm{~mL}$ de carbonato de sódio $20 \%$ e $2 \mathrm{~mL}$ de água destilada. Agitouse depois de 30 minutos, realizou-se a leitura em espectrofotômetro (Spectronic Genesys 2) com comprimento de onda a $770 \mathrm{~nm}$ e o resultado foi expresso em $\mathrm{mg} 100 \mathrm{~g}^{-1}$ de polpa.

Nas avaliações físico-químicas foram utilizadas três repetições constituídas da polpa obtida de amostras compostas de no mínimo $1,0 \mathrm{~kg}$ de frutos para cada repetição. Após a coleta dos dados físico-químicos, os mesmos foram submetidos a análises estatísticas descritivas obtendo-se a média das características de cada genótipo analisado (BANZATTO e KRONKA, 1995).

\section{Resultados e Discussão}

Pode-se verificar para a variável $\mathrm{pH}$, através da Tabela 1, uma variação pequena entre os genótipos, oscilando entre 2,60 a 2,93, apresentando, em geral, média de 2,76. Houve diferença significativa para todos os genótipos estudados.

Todos os genótipos estudados neste trabalho apresentaram valores médios de $\mathrm{pH}$ acima de 2,60. Silva Júnior et al. (2004) trabalhando com frutos de umbu-cajá, apresentou valores que variaram de 1,75 (genótipo 4) a 2,57 (genótipo 10) com valor médio de 2,20, assemelhando-se aos resultados encontrados no presente estudo. Estes valores também foram semelhantes aos encontrados por Santos (1996), Lima et al. (2002) e Silva Júnior et al. (2004), cujas variações de pH para umbu-cajá foram, respectivamente, de: 2,0 a 2,2; 2,11 a 2,17 e 2,5 a 3,0.

No entanto, dentre os genótipos de umbu-cajá estudados por Silva Júnior et al. (2004), destacaram-se o $3,4,13,14,15,17,19,23$ e 26 por apresentarem $\mathrm{pH}<2,20$, estabelecido como atributo de qualidade pela legislação, por favorecer a conservação da polpa, minimizando o crescimento de leveduras (BRASIL, 1999). 
Tabela 1. Quadro geral com amplitude, média, intervalos de confiança e coeficiente de variação das características físico-químicas dos frutos de umbu-cajazeiras.

\begin{tabular}{rrrrrrrr}
\hline Genótipos & \multicolumn{1}{r}{ pH } & \multicolumn{1}{c}{ Ac. Red. } & \multicolumn{1}{l}{ Amido } & \multicolumn{1}{c}{ Pect total } & \multicolumn{1}{c}{ flav } & Caroten & Polifen \\
P1 & 2,7 & 6,3 & 0,1 & 0,3 & 30,6 & 0,4 & 29,1 \\
P2 & 2,6 & 7,2 & 0,1 & 0,6 & 32,7 & 0,7 & 23,5 \\
P3 & 2,9 & 6,2 & 0,3 & 0,5 & 8,5 & 0,8 & 27,2 \\
P4 & 2,8 & 6,4 & 0,1 & 0,3 & 29,9 & 0,8 & 22,5 \\
P5 & 2,8 & 7,7 & 0,2 & 0,3 & 35,1 & 0,9 & 31,7 \\
P6 & 2,7 & 7,7 & 0,1 & 0,3 & 10,6 & 1,1 & 32,3 \\
P7 & 2,8 & 9,0 & 0,1 & 0,4 & 38,7 & 0,2 & 26,9 \\
P8 & 2,8 & 7,3 & 0,2 & 0,4 & 44,8 & 1,1 & 32,8 \\
P9 & 2,8 & 8,4 & 0,1 & 0,2 & 8,1 & 1,2 & 30,3 \\
P10 & 2,7 & 7,8 & 0,1 & 0,3 & 30,5 & 0,8 & 33,4 \\
P11 & 2,9 & 8,4 & 0,2 & 0,2 & 18,6 & 1,0 & 31,0 \\
P12 & 2,7 & 6,8 & 0,2 & 0,6 & 12,7 & 0,5 & 27,9 \\
P13 & 2,8 & 7,7 & 0,2 & 0,4 & 49,9 & 0,6 & 35,5 \\
P14 & 2,9 & 7,9 & 0,1 & 0,4 & 9,0 & 1,0 & 27,1 \\
P15 & 2,8 & 6,3 & 0,2 & 0,4 & 16,6 & 0,5 & 26,2 \\
P16 & 2,7 & 9,7 & 0,3 & 0,4 & 41,8 & 0,6 & 30,5 \\
P17 & 2,8 & 8,7 & 0,1 & 0,3 & 30,2 & 0,9 & 30,0 \\
P18 & 2,6 & 7,4 & 0,1 & 0,4 & 33,9 & 0,6 & 29,0 \\
P19 & 2,8 & 9,4 & 0,2 & 0,2 & 34,1 & 0,8 & 29,7 \\
P20 & 2,6 & 10,4 & 0,2 & 0,5 & 39,0 & 0,6 & 36,3 \\
Média & 2,77 & 7,84 & 0,17 & 0,37 & 27,76 & 0,76 & 29,63 \\
IC95 & 0,02 & 0,35 & 0,02 & 0,03 & 3,55 & 0,07 & 1,10 \\
Máximo & 3,00 & 11,62 & 0,41 & 0,64 & 56,93 & 1,27 & 38,17 \\
Mínimo & 2,60 & 4,25 & 0,04 & 0,15 & 7,64 & 0,22 & 18,39 \\
CV\% & 3,47 & 17,33 & 49,48 & 35,86 & 49,51 & 35,42 & 14,44 \\
\hline
\end{tabular}

$\mathrm{pH} ; \mathrm{AR}=$ açúcares redutores (\%); $\mathrm{AM} .=\operatorname{amido}(\%) ; \mathrm{PT}=$ pectina total $(\%) ; \mathrm{FL}=$ flavonoides amarelos $\left(\mathrm{mg} 100 \mathrm{~g}^{-1}\right)$;

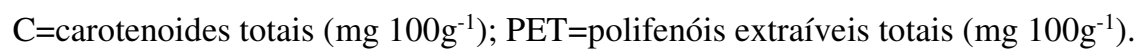

Noronha (2000), estudando frutos de umbu-cajá, constataram para o $\mathrm{pH}$, valores entre: 3,15 e 3,27, sendo superiores aos encontrados no presente estudo e também por Santos (1996) e Lima et al. (1990), com relação ao umbu-cajá; Sacramento et al. (1998) e Lima et al. (1990), em relação ao cajá.

Segundo Lima et al. (2002), ao estudar o pH em frutos de umbu-cajá, verificou que o mesmo manteve-se estável nos diferentes estádios de maturação dos frutos com os valores médios de 2,01 a 2,0, podendo-se observar que as polpas de umbu-cajá no estádio totalmente amarelo apresentaram valores de $\mathrm{pH}$ baixos dos encontrados em outros frutos do gênero Spondias, como cajá apresentando pH de 3,30 (ALDRIGUE, 1988), 2,75 (LIMA et al.,1990) 2,4 a 3,0 (SACRAMENTO e SOUZA, 2000), umbu-azedo com 2,26 e umbu-doce com 2,28 (COSTA, 1998). 
O teor de açúcares redutores (Tabela 1) variou bastante, de 6,23 a 10,35 \%, para os genótipos P20 e P3, respectivamente. Esses valores são compatíveis aos encontrados por Noronha (2000), onde para os açúcares redutores com frutos de umbu-cajá, constataram valores compreendidos entre: 6,77 e 7,70, valores estes inferiores ao encontrado por Sacramento et al. (1998), quando fez as mesmas determinações na polpa do cajá.

A média geral encontrada para açúcares redutores foi de 7,83 \%, valor bem próximo ao relatados por Noronha (2000), com um teor médio de 7,23\%.

Os resultados obtidos para amido apresentaram diferença estatística significativa entre os genótipos de umbu-cajá analisados (Tabela 1), verificando-se variação entre 0,1 a 0,3\%. Entre os genótipos estudados o P3 e P6 foram os que apresentaram os maiores percentuais de amido (0,3\%), diferindo estatisticamente de todos os outros genótipos.

Dois trabalhos são relativamente antigos utilizaram metodologia de determinação de amido: o de Hubbard, Pharr e Huber (1991), que não especifica o cultivar e estádio de maturação da manga e o de Castrillo, Kruger e Whathey (1992), que especifica ambos. Os dois grupos de pesquisadores, após encontrarem menos de $1 \%$ de amido em mangas, valor semelhante ao que foi encontrado no presente estudo, verificaram um aumento considerável no teor de sacarose acumulada, concluindo que o teor de amido inicial era insuficiente para fornecer o carbono necessário à síntese da sacarose, nas quantidades acumuladas após a colheita.

Filgueiras et al. (2000), trabalhando com ciriguela do mesmo gênero do umbu-cajá, observou uma degradação acentuada de amido desde o estádio verde até o maduro. Sousa et al. (1998), trabalhando com ciriguela mexicana em três estádios de maturação, encontraram uma redução de mais de 80 \% no conteúdo de amido depois de três dias em frutos colhidos verdes.

Martins e Melo (2008) comentaram que no caso do cajá pode haver o comprometimento do sabor pelo alto teor de amido. Nesse estudo, foram reportados teores de amido de 1,92 \% para frutos predominantemente amarelos e $0,52 \%$ para frutos amarelos.

De acordo com as análises realizadas para pectina total, houve diferença estatística significativa entre os genótipos avaliados. A menor percentagem de pectina total foi observada no genótipo P9, P11 e P19 com 0,2 \%, destacando-se com maior teor o genótipo P2 com valor equivalente de 0,6\%. A média geral para as todos os genótipos em estudo foi de 0,37 \% (Tabela 1).

Dados de teor de pectina total em umbu-cajá praticamente inexiste na literatura, com exceção do trabalho realizado por Torres et al. (2003), onde trabalhando com frutos de umbu-cajá, verificou que o valor de pectina para a amostra a $9{ }^{\circ}$ Brix. O valor citado por Policarpo et al. (2002) de pectina total de $0,63 \mathrm{mg} 100 \mathrm{~g}^{-1}$ para a polpa de umbu encontra-se próximo ao da amostra a $18^{\circ}$ Brix. Na polpa integral $\left(13^{\circ}\right.$ Brix $)$ o teor de pectina de $0,57 \%$ de pectato de cálcio, representa um conteúdo, relativamente, pobre, se comparado com outros frutos, tais como: limão (3 a 4 \%), 
banana $(0,7$ a $1,2 \%)$ e maçã $(0,5$ a 1,6 \%) (FOGARTY e WARD, 1972). O teor de pectina aumentou cerca de $6 \%$ na polpa a $24{ }^{\circ}$ Brix com relação à polpa integral, sendo as substâncias pécticas os principais componentes químicos dos tecidos quais são responsáveis pelas mudanças de textura dos frutos (CHITARRA e CHITARRA, 2005).

Comparando os resultados encontrados nessa pesquisa com os de outras frutas, pode-se afirmar que o umbu-cajá apresenta alto teor de pectina total, já que a maioria das frutas tidas como ricas em pectinas apresenta teores semelhantes à média deste estudo, tais como: uva $(0,81 \%)$, maçã $(0,71 \%)$, amora $(0,59 \%)$ e groselha vermelha $(0,58 \%)$ (Processo de geleificação em alimentos, 2007).

De forma geral os genótipos analisados apresentaram diferença significativa quanto ao teor de flavonoides amarelos (Tabela 1), apresentando mínimo de $8,10 \mathrm{mg} 100 \mathrm{~g}^{-1}$ e máximo de 49,92 mg $100 \mathrm{~g}^{-1}$, com média geral de 27,76 mg 100 g-1. O genótipo P13 apresentou maior média de teor de flavonoides amarelos, com um valor médio em torno de $49,92 \mathrm{mg} 100 \mathrm{~g}^{-1}$, diferindo significativamente dos demais genótipos analisados.

Não há relatos na literatura sobre estes compostos em frutos de umbu-cajá, apesar dos bons teores de flavonoides amarelos determinados neste estudo, pois apresentaram conteúdo semelhante ao caju que contém grandes quantidades de flavonoides amarelos, o que pode ser confirmado por Moura et al. (2001), no qual determinaram variação no teor de 80,62 a $129,69 \mathrm{mg} 100 \mathrm{~g}^{-1}$, com média de $105,12 \mathrm{mg} 100 \mathrm{~g}^{-1}$ em sua pesquisa com nove diferentes clones de cajueiro. Vale ressaltar que esses resultados foram determinados na película do caju, enquanto no umbu-cajá essa grande quantidade de flavonoides amarelos está presente na polpa.

Lima et al. (2000), trabalhando com acerola, verificaram teores de flavonois totais que

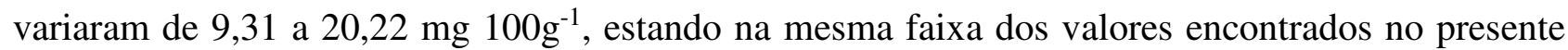
estudo. No que se refere aos teores de flavonoides totais, nos frutos de umbu-cajá, os valores foram estatisticamente diferentes entre si.

Fennema (1993), os flavonois (quercetina) e as flavonas (luteolina) são os grupos de flavonoides responsáveis pela cor amarela que sempre acompanham as antocianinas em frutos, provavelmente porque apresentam vias biossintéticas semelhantes. Estes pigmentos pertencem ao grupo dos flavonoides que têm sido relatados como compostos que possuem capacidade antioxidante (PIETTA, 2000). Os resultados indicam que o umbu-cajá é boa fonte de outros flavonoides com propriedades funcionais, contribuindo para o seu valor nutricional.

Os teores médios de carotenoides totais dos genótipos apresentaram diferença estatística significativa, com uma grande variação entre os genótipos P7 e P9, com no mínimo 0,23 mg $100 \mathrm{~g}^{-1}$ a $1,21 \mathrm{mg} 100 \mathrm{~g}^{-1}$. A média geral encontrada foi de $0,75 \mathrm{mg} 100 \mathrm{~g}^{-1}$ e o coeficiente de variação de $35,42 \%$ (Tabela 1). Destacando-se entre os genótipos o P9, P8 e P16, com valor médio de 1,21 mg 
$100 \mathrm{~g}^{-1}$. Os demais genótipos apresentaram teores de carotenoides inferiores a $1,0 \mathrm{mg} 100 \mathrm{~g}^{-1}$, observando-se a menor concentração no genótipo P7, com um valor médio de $0,23 \mathrm{mg} 100 \mathrm{~g}^{-1}$.

Comparando os resultados encontrados nessa pesquisa com outras frutas, pode-se afirmar que o umbu-cajá apresenta um bom teor de carotenoides totais, já que a maioria das frutas consideradas ricas nessa substância apresenta teores superiores à média deste estudo, tais como: manga com 1,91 a 2,63 mg $100 \mathrm{~g}^{-1}$ (RIBEIRO, 2006), goiaba vermelha (6,21 mg $\left.100 \mathrm{~g}^{-1}\right)$, pitanga

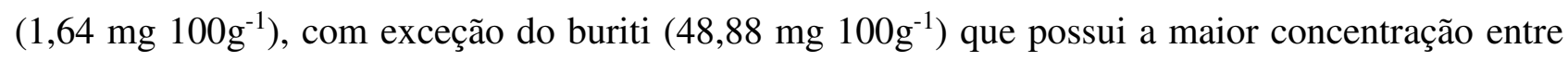
as fontes já analisadas no Brasil (GODOY e RODRIGUEZ-AMAYA, 1998).

Entretanto, comparando os resultados encontrados nessa pesquisa com outras frutas, como por exemplo, o mamão, com um teor de carotenoides totais em torno de $0,85 \mathrm{mg}^{100 \mathrm{~g}^{-1}}$ (GODOY e RODRIGUEZ-AMAYA, 1998), pode-se afirmar que o umbu-cajá apresenta um teor de

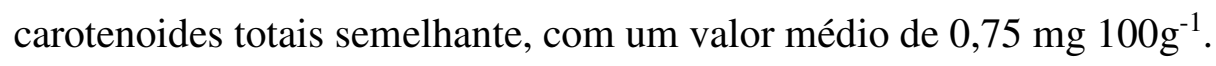

Com os resultados obtidos pode-se verificar que o umbu-cajá possui um bom teor em carotenoides totais. Segundo Zanatta (2004) devido à grande diferença estrutural entre carotenoides e antocianinas, poucos pesquisadores determinaram à composição de ambos os pigmentos na mesma amostra.

Hamano e Mercadante (2001), em estudo da composição de carotenoides em produtos comerciais de cajá, encontraram para o suco integral de cajá valores de $16,71 \mu \mathrm{g} \cdot \mathrm{g}^{-1} \mathrm{e} 88,7 \mu \mathrm{g} .100 \mathrm{~g}^{-}$ ${ }^{1}$ para carotenoides totais e vitamina A, respectivamente. Os valores obtidos, no presente trabalho, são inferiores; porém, na formulação do produto, foram utilizados $30 \%$ da polpa do fruto. Não foram encontrados dados na literatura para carotenoides totais em umbu-cajá.

A distribuição dos carotenoides em frutos é extremamente complexa e sujeita á consideráveis variações (GROSS, 1987). Alguns dados reportados, afirmam que os carotenoides são geralmente mais concentrados na película do que na polpa de alguns frutos. Em abacates, por exemplo, o teor de carotenoides totais na polpa variou de $10-14 \mu \mathrm{g} . \mathrm{g}^{-1}$ de peso fresco enquanto na

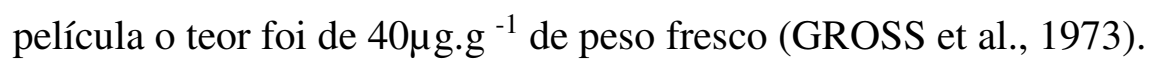

Os teores médios de polifenóis extraíveis totais (Tabela 1) dos genótipos apresentaram diferença estatística significativa, apresentando considerável variação entre os genótipos, oscilando entre valor mínimo de $22,5 \mathrm{mg} 100 \mathrm{~g}^{-1}$ referente ao genótipo $\mathrm{P} 4$ ao máximo de $36,03 \mathrm{mg} 100 \mathrm{~g}^{-1}$ para o genótipo P20. A média geral para os genótipos em estudo foi de 29,63 mg $100 \mathrm{~g}^{-1}$.

Estes resultados foram inferiores aos relatados por Hassimotto et al. (2005), que determinaram o teor de polifenóis totais em polpa de frutas e encontraram valores como por

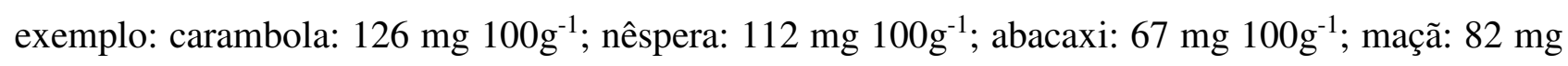

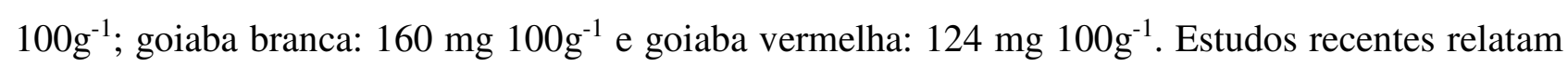
que compostos fenólicos têm se mostrado bons contribuintes para a capacidade antioxidante total 
dos alimentos que os contêm, embora sua relevância nutricional seja incerta pela sua pobre absorção e rápida metabolização, associada a sua limitada ação antioxidante in vivo (ZULUETA et al., 2007). Não foram encontrados na literatura dados relativos à polifenóis extraíveis totais em umbu cajá.

\title{
4. Conclusões
}

Os frutos de umbu-cajazeira, em geral, independente do genótipo estudado, apresentaram bons teores de açúcares redutores e pectina total, indicando potencial para o consumo "in natura".

Os genótipos de umbu-cajá analisados contêm em sua composição substancial presença de substâncias biologicamente ativas, principalmente os relacionados a compostos fenólicos e pigmentos, tais como: flavonoides amarelos, carotenoides totais e polifenóis extraíveis totais, constituem uma fonte potencial de antioxidantes naturais para a dieta humana.

\section{Agradecimentos}

À CAPES pelo auxílio à pesquisa e ao Dr. Ricardo Elesbão Alves (Embrapa Agroindústria Tropical).

\begin{abstract}
The 'umbu-caja' is a fruit tree species belonging to the Anacardiaceae family which has spontaneous occurrence in the semiarid region of Northeast, Brazil. This work of research aimed to evaluate the quality of fruits of the tree umbu-cajazeiras (Spondias sp.), from different genotypes, through of physical-chemistry characterization. The harvest was carried for all the genotypes in the same day, in the March of 2007, being the fruits removed in the stage of commercial maturation with aid of hook, where the maturity indicative was the yellow-orange color of rind. The fruits used in the experiment were harvested from twenty source plants of the tree umbu-caja proceeding from the town Iguatu, CE. The following parameters were evaluated: reductors sugars, $p H$, starch, total pectin, total carotenoids, yellow flavonoids and total extractable polyphenols. In a way, it had a variation between the genotypes, for all the evaluated physical-chemistry characteristics. With regard to the evaluated attributes of quality, the average $\mathrm{pH}$ of 2,77 , hight content reductors sugars $(7,84 \%)$, low for starch $(0,17 \%)$ and pectin $(0,37 \%)$. The general total carotenoids was $0,76 \mathrm{mg}$ $100 \mathrm{~g}^{-1}$, yellow flavonoids $27,76 \mathrm{mg} 100 \mathrm{~g}^{-1}$ and total extractable polyphenols $29,63 \mathrm{mg} 100 \mathrm{~g}^{-1}$, factor this of great importance for the industry.
\end{abstract}

Key words: Spondias sp.; attributes; quality; semiarid. 


\section{Referências}

ALDRIGUE, M.L. Desenvolvimento e validação de metodologia analítica, utilizando a CLAE, para determinação de vitamina $\mathbf{C}$ em frutas e seus principais produtos. 160f. Tese (Doutorado em Ciência de Alimentos) - Faculdade de Engenharia de Alimentos, Universidade Estadual de Campinas, Campinas, 1988.

ALVES, R. E.; BRITO, E. S.; RUFINO, M.S.M. Prospecção da atividade antioxidante e de compostos com propriedades funcionais em frutas tropicais. In: Congresso Brasileiro de Fruticultura, 19, 2006, Cabo Frio. Palestras e resumos...Cabo frio-RJ: SBF/UENF/UFRuralRJ, p. 133-141. 2006.

ASSOCIATION OF OFFICIAL ANALYTICAL CHEMISTRY. Official methods of analysis of the Association of Official Analytical Chemistry.11.ed.Washington: AOAC, 1992. 1115p. 1992.

BAIARDI, A.; OLALDE, A.R.; MENDES, L.N.; MENDES, R.J. Potencial e possibilidade de exportação das frutas tropicais brasileira: a qualidade...In: CONGRESSO BRASILEIRO DE ECONOMIA E SOCIOLOGIA RURAL, 2001, RECIFE. Anais...PIRACICABA-SP: SOBER, V. único. p. 78-90, 2001.

BANZATTO, D. A.; KRONKA, S. N. Experimentação agrícola. 3. ed. Jaboticabal: FUNEP/ UNESP-FCAV; 247p, 1995.

BRASIL. MINISTÉRIO DA AGRICULTURA E DO ABASTECIMENTO. Instrução Normativa $\mathrm{n}^{\circ} 12$, de 10 de setembro de 1999. Aprova os Padrões de Identidade e Qualidade para Polpas de Frutas. Brasília. 1999.

CASTRILlO, M; KRUGER, N.J; WHATHEY, F.R. Sucrose metabolism in mango fruit during ripening. Plant Science, Shannon, v. 84, n. 1, p. 45-51, 1992.

CHITARRA, A. B.; CHITARRA, M. I. F. Pós-colheita de frutos e hortaliças: fisiologia e manuseio, Lavras: UFLA, $2^{\circ}$ edição, 785p. 2005.

COSTA, N.P. Desenvolvimento, maturação e conservação pós-colheita de frutos da cajazeira (Spondias mombin L.), Areia, 1998. 97f. Dissertação (Mestrado no Curso em Produção Vegetal) - Universidade Federal da Paraíba, 1998.

FENNEMA, O. R. Química de los alimentos. Editora Acribia, S. A. Zaragoza, Espanha, 1095p. 1993.

FILGUEIRAS, H.A.C.; MENEZES, J.B.; ALVES, R.E; COSTA, F.V.; PEREIRA, L.S.E.; GOMES JÚNIOR, J. Colheita e manuseio pós-colheita. Melão pós-colheita: Brasília: EMBRAPA - SPI/FRUTAS DO BRASIL, p.23-41. (Frutas do Brasil, 10). 2000.

FOGARTY, W.M.; WARD, O.P. Pectic substances and pectinolytic enzymes. Process Biochemistry, v. 7, p. 13-17, 1972.

FRANCIS, F. J. Analysis of anthocyanins. In: MARKAKIS, P. (ed). Anthocyanins as food colors. New york: Academic Press, p.181-207, 1982.

GIACOMETTI, D.C. Recursos genéticos de fruteiras nativas do Brasil. In: SIMPÓSIO NACIONAL DE RECURSOS GENÉTICOS DE FRUTEIRAS NATIVAS, 1992, Cruz das Almas, BA. Anais...Cruz das Almas: Embrapa-CNPMF, p.13-27, 1993.

GODOY, H.T.; RODRIGUEZ-AMAYA, D.B. Occurence of cis-isomers of provitamin A in Brazilian vegetables. J. Agric. Food Chem; v. 46, p. 3081-3086, 1998.

GROSS, J.; GABAI, M.; LIFSHITZ, A.; SKLARZ, B. Carotenoids in pulp, peel and leaves of Persea americana. Phytochemistry, v. 12, p.2259-2263, 1973.

GROSS, J. Pigments in fruits. London: Academic Press, 303p. 1987.

HAMANO, P.S.; MERCADANTE, A.Z. Compositions of carotenoids from commercial products of caja (Spondias lutea). Journal of Food Composition and Analysis, v. 14, n. 4, p. 335-343, ago; 2001.

HASSIMOTTO, N.M.A.; GENOVESE; M.I.; LAJOLO, F.M. Antioxidant activity of dietary fruits, vegetables, and comercial frozen pulps. J. Agric. Food Chem; v. 53, n. 8, p. 2928-2935, 2005. 
HIGBY, W.K. A simplified method for determination of some the carotenoid distribution in natural and carotenefortified orange juice. Journal of Food Science, Chicago, v. 27, p.42-49, 1962.

HUBBARD, N.L; PHARR, D.M; HUBER, S.C. Sucrose-phosphate synthase and other sucrose metabolizing enzymes in fruits of various species. Physiologia Plantarum, Copenhagen, v.82, p.191-196, 1991.

LARRAURI, J.A.; PUPÉREZ, P.; SAURA-CALIXTO, F. Effect of drying temperature on the stabilitity of polyphenols and antioxidant activity of red grape pomace peels. J. Agri. Food Chem. v. 45, p. 1390-1393, 1997.

LIMA, E. D. P. A.; CARDOSO, E.A.; SILVA, H; LIMA, C.A.A.; SILVA, A.Q. Características tecnológicas de frutos do gênero Spondias, família Anacardiaceae. In: REUNIÃO NORDESTINA DE BOTÂNICA, 1; Recife. Anais...p.109, 1990 .

LIMA, V. L.A.G.; MELO, E. A.; LIMA, L.S.; NASCIMENTO, P.P. Flavonoides em seleções de acerola. Ciência Rural, Santa Maria, v.30, n.6, p.1063-1064, 2000.

LIMA, E.D.P.A.; LIMA, C.A.A.; ALDRIGUE, M.L.; GONDIM, P.J.S. Caracterização física e química dos frutos de umbu-cajazeiras (Spondias sp.) em cinco estádios de maturação, da polpa congelada e néctar. Rev. Bras. Frutic; Jaboticabal-SP, v.24, n.2, p.338-343, 2002.

LOPES, W.F. Propagação assexuada de cajá (Spondias mombin L.) e umbu-cajá (Spondias sp.) através de estacas. Areia, 47p. (Relatório final PIBIC - CNPq). 1997.

MARTINS, S.T, MELO, B. Spondias (cajá e outras). Núcleo de Estudo em Fruticultura no Cerrado. Disponível em: Www.fruticultura.iciag.ufu.br/caja.html. 2008.

McCREADY, R. M.; McCOMB, E. A. Extraction and determination of total pectic material in fruits. Analytical Chemistry, Washington, v. 24, n. 12, p.1586-1588, 1952.

MILLER, G.L. Use of dinitrosalicylic acid reagent for determination of reducing sugars. Analytical Chemistry, Washington, v. 31, p. 426-428, 1959.

MITCHELL, J.D; DALY, D.C. Revisão das espécies neotropicais de Spondias (Anacardiaceae). In: CONGRESSO NACIONAL DE BOTÂNICA, 46, Ribeirão Preto, Resumos...Ribeirão Preto: USP, p.207. 1995.

MOURA, C. F. H.; AlveS, R. E.; INNECCO, R.; FIlGUEIRAS H. A. C.; MOSCA, J. L.; PINTO, S. A. A. Características físicas de pedúnculos de cajueiro para comercialização in natura. Rev. Bras. Frutic; Jaboticabal, v. 23, n. 3, 2001.

NORONHA, M.A.S. Propagação vegetativa da cajarana (Spondias sp.) por estaquia. Mossoró, RN: ESAM. Monografia (Graduação em Agronomia) - Departamento de Fitotecnia, ESAM. 1997.

NORONHA, M.A.S. Características físico-químicas de frutos de umbu-cajá (Spondias sp.) provenientes dos pólos Baixo-Jaguaribe (CE) e Assu-Mossoró (RN). Revista Brasileira de Produtos Agroindustriais. Campina-Grande, v. 2 , n. 2, p.91-96, 2000.

PIETTA, P.G. Flavonoids as antioxidants. Journal of Natural Products, v. 63, n. 7, p. 1035-1042, 2000.

POLICARPO, V.M.N.; RESENDE, J.M.; ENDO, E.; BORGES, V.; CAVALCANTI, N.B.; OLIVEIRA, V.M. In: Congresso Brasileiro de Ciência e Tecnologia de Alimentos, 18., 2002, Porto Alegre. Anais...Porto Alegre: SBCTA, 2002. CD Rom. 2002.

PROCESSO DE GELEIFICAÇÃO EM ALIMENTOS. Disponível <http://br.geocities.com/abgalimtec/geleificacao.html>. Acesso em: 17 fev. 2007.

RIBEIRO, S.M.R. Caracterização e avaliação do potencial antioxidante de mangas (Mangifera indica L.) cultivadas no Estado de Minas Gerais. 149f. Tese (Doutorado em Bioquímica Agrícola) - Universidade Federal de Lavras, Minas Gerais, 2006.

SACRAMENTO, C.K.; BARRETO, W.S.; LOPES, J.R.; LEITE, J.B.V. Características físico-químicas de cajás (Spondias mombin L.) oriundos de diferentes locais da região Sudeste da Bahia. In: Congresso Brasileiro de Fruticultura, 15, 1998, Poço de Caldas, Anais...Poços de caldas: SBF/ UFLA, 1998. v.1, p.168. 1998. 
SACRAMENTO, C.K.; SOUZA, F.X. Cajá (Spondias mombin L.) Jaboticabal: Funep, 42p. (Série Frutas Nativas, 4). 2000.

SANTOS, G.M. Caracterização de frutos de cajá (Spondias mombin L.) e umbu-cajá (Spondias sp.) e teores de NPK em folhas de frutos. Areia: UFPB/CCA, 1996, 49p. (Monografia de Graduação). 1996.

SILVA JÚNIOR, J. F.; BEZERRA, J.E.F.; LEDERMAN, I.E.; ALVES, M.A.; MELO NETO, M.L. Collecting, ex situ conservation and characterization of "cajá-umbu" (Spondias mombin x Spondias tuberosa) germ-plasm in Pernambuco State, Brazil. Genetic Resources and Crop Evolution, 51: 343-349. 2004.

SOUZA, F.X.; SOUZA, F.H.L.; FREITAS, J.B.S. Caracterização morfológica de endocarpos de umbu-cajá. In: 48 CONGRESSO NACIONAL DE BOTÂNICA, Crato, CE. Resumos...Fortaleza: SBB/BNB, p.121. 1997.

SOUSA, R.P., FILGUEIRAS, H.A.C., ALVES, R.E., COSTA, J.T.A., OLIVEIRA, A.C. Identification of harvest stage for red mombin (Spondias purpurea L.). Proc. Interamer. Soc. Trop. Hort. 42:319-324. 1998.

TORRES, L.B.V.; QUEIROZ, A.J.M.; FIGUEIRÊDO, R.M.F. Viscosidade aparente da polpa de umbu-cajá concentrada a $10^{\circ} \mathrm{C}$. Revista Brasileira de Produtos Agroindustriais, Campina Grande, v.5, n.2, p.161-168, 2003.

ZANATTA, C.F. Determinação da composição de carotenóides e antocianinas de camu-camu (myrciaria dubia). 144f. Tese (Mestrado em Ciência de Alimentos) UNICAMP, Campinas, 2004.

ZULUETA, A. et al. Vitamin C, vitamin A, phenolic compounds and total antioxidant capacity of new fruit juice and skim milk mixture beverages marketed in Spain. Food Chemistry, v. 103, n. 4, p. 1365-1374, 2007. 